\title{
A reflection on the University of Edinburgh's policy on sexual harassment
}

Gavin Douglas, Deputy

Secretary of the University

(Student Experience) 
I very much enjoyed Chris' article which makes a number of powerful and important points.

The No One Asks For It campaign has very much been a joint initiative between the University, the Student's Association and the Sports Union - not "driven" by the University but conceived and delivered in partnership between all three groups. The campaign visuals are certainly and deliberately provocative, possibly shocking - but we tested them carefully pre-launch with current students and with the chair of a local women's support organisation and took on board their feedback and suggestions. We were really pleased that the campaign attracted the support of senior leaders including the University Principal, the President of EUSU (Edinburgh University Sports Union) and Chris herself.

Do campaigns like No One Asks For It actually "work"? We can of course use marketing techniques to track campaign success by clicks, likes, shares, page views and signups. But these do not really tell us anything very important about whether attitudes have changed one jot, or whether survivors of sexual violence feel better supported. We do know that the number of students coming forward to disclose incidents of sexual violence has gone up significantly this year. We can't say whether this is because of the campaign and the new guidelines or not, but we think this increase is a good thing - though we recognise that we are still only dealing with the tip of the iceberg.

We also know that the campaign has not led to structural change in the University or to cultural change in the groups of people that make up the University community. A single campaign was never going to do that. But change in universities, which are complex organisations, is itself a complex thing.
Fullan \& Scott (2009), senior academics who have written extensively on the leadership of change in higher education, approvingly quote Francis Bacon: "We rise to great heights by a winding staircase". A year on, you stop, look back and think - what have we achieved? What have we learned? What do we need to do to get to the next level? Chris' article is really helpful in this context.

We argue that we have come some way this year with the campaign and the new guidelines; we are seeing more students disclosing and we collectively - the University and student groups - are supporting more students who are survivors of sexual violence. All this is good in terms of progress with tackling sexual violence on campus.

But that doesn't mean, as Chris suggests, that anyone - including the University - is now ready to take a back seat. In fact we think we need to step up the focus in this area and do more to a) change the culture and $b$ ) do a better job of supporting survivors. We think this will require a greater, more co-ordinated and strategic response from the University - senior leaders, students, academic staff, professional services staff, working alongside other partners such as Rape Crisis Scotland and Police Scotland. We are very confident that this work will continue and grow in 2017/18 - and beyond. 